\title{
FACTORS AFFECTING SEASONALITY IN THE STOCK MARKET: A SOCIAL NETWORK ANALYSIS APPROACH
}

\author{
Ms. K. Kajol \\ Research Scholar \\ Department of Management Studies \\ Indian Institute of Information Technology Allahabad \\ Prayagraj-211015 \\ Uttar Pradesh, India \\ E-mail: kajol.1095@gmail.com \\ Ms. Mausami Nath \\ Department of Business Administration \\ Assam University (A Central University) \\ Silchar-788011 \\ Assam, India \\ E-mail: mausaminath2015@gmail.com

\section{Dr. Ranjit Singh} \\ Associate Professor \\ Department of Management Studies \\ Indian Institute of Information Technology Allahabad \\ Prayagraj-211015 \\ Uttar Pradesh, India \\ E-mail: ranjitsingh@iiita.ac.in

\section{Prof. H. Ramananad Singh} \\ Professor \\ Department of Business Administration \\ Assam University (A Central University) \\ Silchar-788011 \\ Assam, India \\ E-mail: singhhaomom@gmail.com

\section{Dr. Amit Kumar Das} \\ Assistant Professor \\ Department of Business Administration \\ Assam University (A Central University) \\ Silchar-788011 \\ Assam, India \\ E-mail: amitdas.au@gmail.com
}




\begin{abstract}
The study aims at identifying the factors influencing the seasonality effect in the stock market and further identifying the relationship between the influencing factors. The study aims at conducting a complete analysis of the influencing factors along with measuring their impact on seasonality using Social Network Analysis (SNA). The factors affecting the seasonality effect in the stock market were identified through the literature review. Experts' opinions were sought for determining the relationship among the factors and finally, the importance of those factors was analyzed using Social Network Analysis (SNA). It was found that volatility is the most important factor affecting the other factors of seasonality and consequently seasonality effect finally. Besides, earning announcements, dividend, and January effects strongly influence the effect of seasonality in the stock market because of their higher in-degree and out-degree. To understand the mechanism of the stock market, the policymakers need to impart training to the investors through awareness campaign or by opening learning investors' Club at different places. With this they can evaluate their standing in the stock market and the capability of bearing the risk which, in the long run, will be reflected in their investment behavior along with that the culture of equity investing will also be promoted among the investors.
\end{abstract}

Keywords: Seasonality Effect; Stock Market; Social Network Analysis (SNA); Efficient Market Hypothesis (EMH)

\title{
INTRODUCTION
}

The Seasonality effect in the stock market refers to a diverse set of findings which shows that stock returns are higher on some days of the week and some times of the month and some months of the year considering as calendar anomalies in the market. Ever since Wachtel (1942) observed seasonality in the Dow Jones, it became an important matter of discussion worldwide. He found evidence of seasonal patterns from the US stock market by taking the industrial average's from 1927-1942. In the sequence of data, seasonality is the presence of anomalies that occurs at regular intervals less than a year in a specific manner (Guo \& Wang, 2008). The periodic fluctuation in a time series provides evidence of seasonality which leads us to the presence of various factors. Anomalies are irregularities, which create a diversion from the normal or routine order (Safeer \& Kevin, 2014). Frankfurter and McGoun (2001) said that the word anomaly is not a simple coincidence rather a sophisticated one and need to handle carefully. Through abundant research on seasonal anomalies on the stock market evidence showed that there are different kind of anomalies namely the weekend effect, the turn-of-themonth effect, the turn-of-the-year effect, the January effect, sell in May and go away, lunar effect, holiday effect, etc. and these are well documented (Singh, 2009). The presence of seasonality in the financial market leads to earning abnormal profit by predicting the timing of selling and buying of stocks. Due to that reason, the investors are keen to know whether seasonality is present in the stock market or not. Seasonality is also much important to consider having track of which factors are affecting economic growth. However, the presence of seasonality in stock returns contradicts the existence of the Efficient Market Hypothesis (EMH) (Fama, 1970). It is a hypothesis in financial economics which states that stock prices reflect all the available information and the future stock prices followed a random pattern, which cannot be predicted. Market efficiency has been a long time debated topic.

Rozeff and Kinney (1976) were the first to confirm Wachtel's observation of seasonal patterns in an equal-weighted index of the New York Stock Exchange. Keim (1983) found that the US stock market reported that due to January abnormal returns there was nearly fifty percent 
of the average magnitude of the 'size effect' over the period 1963-1979. Gultekin and Gultekin (1983) found evidence of a seasonal pattern. Each year the stock market tends to repeat certain seasonal trends and this affects individual stock and the market as a whole. These kinds of periodic anomalies occurring simultaneously throughout the year may help an investor to earn a significant amount of profit.

Past researchers have recognized a large number of factors that affect seasonality in the stock market. However, the impact of the factors influencing seasonality is still not known. The present study tries to fills the gap of earlier research on the seasonality effect that seldom analyzes the relationship between different influencing factors. The objectives of the study are threefold. The first objective of the study is to identify the important factors influencing the seasonality effect in the stock market. The second objective is to identify the relationship between the influencing factors and to find out the relevant factors which can develop the study of seasonality effect further. The third objective is to conduct a complete analysis of the influencing factors and measure their impact on seasonality effect using SNA. The study attempts to find out the answer to the following research questions:

a. What are the factors that affect seasonality in the stock market?

b. Are these factors equally important?

c. Is there any interrelationship between the factors?

d. How these factors collectively impact the seasonality effect in the stock market?

The remaining part of the paper is structured as follows: Section 2 of this paper contains the list of influencing factors based on prior literature; Section 3 describes the methodology with a brief description of the SNA; Section 4 contain the analysis and the interpretation part; Section 5 shows the discussion about the research; the conclusion and the limitation are presented in section 6 .

\section{REVIEW OF LITERATURE AND IDENTIFICATION OF FACTORS AFFECTING} SEASONALITY

The presence of seasonality is accepted by Wachtel (1942) and it is well documented by many researchers like Rozeff and kinney (1976); Lakonishok and Smidt (1988); Keim (1983); Boudreaux (1995); Husain (1998); Seyyed et al. (2005); Al-Hajieh et al. (2011); Białkowski et al. (2012); Anjum (2020). There are some factors which are the reasons for the occurrence of the seasonality effect; they are presented as mentioned below:

a. Ramadan Effect (RE): Białkowski et al. (2012) define Ramadan effect as the occurrence of abnormal return enjoyed by investors due to the Psychological-religious effect which drives the moment of the stock market returns. Husain (1998); Seyyed et al. (2005); AlHajieh et al. (2011), and Majeed et al. (2015) found that during the Ramadan months stock return volatility declines as a result investors face less risk. Jebran and Chen (2017) further investigated and found no Ramadan effect in the Pakistan Stock Exchange.

b. Diwali Effect (DE): Kushwah and Munshi (2018) said investors cannot book abnormal profit with the advantage of seasonality because of no significant differences in the return during Diwali.

c. Budget (B): Kushwah and Munshi (2018) found that the budget announcement has no significant difference in the return. However, Varadharajan and Vikkraman (2011) states that there is always a negative return in the market after the budget.

d. Size Effect (SE): Keim (1983) found that stock return is more pronounced for the portfolios of the small firms than the large firm. Reinganum (1983) found that previous years' 
slow-performing small firms provide higher January returns. Rozeff and kinney (1976) confirmed that the January effect is primarily a small firm fact. Whereas, Addinpujoartanto (2019) found a high return on the large firms as compared to a small firms. Heston and Sadka (2008) explain neither industry nor size determines the returns of the market.

e. January Effect (JE): Among the month of the year effect, the January effect is most studied and well documented around the world. This effect states that stock returns are higher in January as compared to another month of the year which is normally caused by significant low return in December. Wachtel (1942) reported the January effect. Rozeff and Kinney (1976); Keim (1983); Reinganum (1983); Thaler (1987); Boudreaux (1995); Das and Rao (2011); Ahsan and Sarkar (2013); Ullahet al. (2016); Avdalović and Milenković (2017); Addinpujoartanto (2019); Singh and Das (2020) found that January month creates a major impact on the seasonality effect by providing higher return during January. Gultekin and Gultekin (1983) explains that people sell their losing stock at the end of the year to pay less tax.

f. Trading Volume (TV): Heston and Sadka (2008) study found that trading volume and intra-month volatility exhibit seasonality. Kang (2010) opines that a seasonal trading volume can affect a stock price; leading to a seasonal return pattern. Bailkowski et al. (2010) found no discernible differences in trading volume in Ramadan month. Similarly, Easterday (2009) concluded that volume of trading in the month of December and January is same as the trading volume of other months.

g. Window Dressing (WD): Addinpujoartanto (2019) mentioned that investors sell their shares to make their portfolios better at the end of the year which creates a negative impact on seasonality.

h. Monthly Effect (ME): Boudreaux (1995) found evidence of monthly effect in US stock from three out of seven countries market and said that the possible reason for the monthly effect can be dividend effect, economic and political announcement in a particular month. But Anjum (2020) in the study of market anomalies prior to and after the establishment of the Pakistan Stock Exchange does not provide any evidence of a monthly effect.

i. Days of the Week Effect (DWE): Keim and Stambaugh (1984); Lakonishok and Smidt (1988); Chowdhury, Sadique and Rahman (2001); Jebran and Chen (2017); and Anjum (2020) found that Friday returns are high as compared to the other days of the week. Kuria and Rio (2013) defines that most of the bad news comes at the beginning of the week and investor to sell their investment which results in a negative return on Monday. However, Singh \& Das (2020) suggested that Day of the week effect is not observed in the Banking and Information Technology sector.

j. Investors' Sentiment (IS): Al-Haijeh et al. (2011) magnified that investor's mood and sentiment are affected by the positive or negative environment and hence create an impact on trading activities. However, Cooper et al., (2005) did not found any such trend.

k. Market Crash (MC): Dash et al., (2011) study suggests that market crashes reduce the seasonal effect as a result there remains a negative impact in the market.

1. Financial Crisis (FC): Varadharajan and Vikkraman (2011) noticed a sharp fall in the market capitalization and indices during the financial crisis hence creates a negative impact on the seasonal pattern of the market. However, Kok and Wong (2004) found no evidence of seasonal anomalies.

m. Transactional Cost (TC): Heston and Sadka (2008) report that with the increase of return the transactional cost also increases which determines seasonal variation in expected stock return and accordingly investors postponed their transaction in the market. 
n. The Dividend (D): Lakonishok and Smidt (1988) in the study noticed that dividends would not lead to any changes in the monthly rate of return seasonality. Heston and Sadka (2008) informed that the trading activity is affected by dividend announcement information but profitability is not associated with it. Boudreaux (1995) explains dividend effect occurs due to the monthly effect.

o. Volatility (V): Husain (1998); Sayyed et al., (2005); Bailkowski et al., (2010) documented a systematic decline in the stock market volatility during Ramadan month. Heston and Sadka (2008) exhibit seasonality with that trading volume and intra-month volatility. Kim (2006) suggested that the risk factor is related to earnings information and the uncertainty is caused by earnings volatility. Mustafa and Nishat (2008) shows the explanatory power of trading activity with trading volume and volatility.

p. Change in Financial Year (CFY): Kushwah and Munshi (2018) found that the change in the financial year had a direct relation with Nifty return and positive correlation but the event showed no significant differences in the return.

q. Investors' Psychology (IP): Bailkowski et al., (2010) sense an optimistic belief during Ramadan which positively impacts investors' psychology that drives their investment decision making. Singh (2010a) also arrived at a similar finding.

r. Liquidity (L): Eleswarapu and Reinganum (1993) provide evidence of liquidity premium only for January which positively impacts the seasonality pattern. Addinpujoartanto (2019) states that shares are traded easily when there is higher liquidity on the company's share.

s. Earnings Announcement (EA): Earning announcement is seasonal and contains specific information about the firm. Heston and Sadka (2008) explains that winner-loser strategies are concentrated around the earnings announcement and further concludes in the study that positive return to annual winner-loser strategies are not associated with earnings and represents a distinct anomaly.

t. End of December Return (EDR): Lakonishok and Smidt (1988) mentioned that the last half of December has high returns because of two major holidays -Christmas and New Year Day.

u. Sell in May and Go Away (SIMGA): Schabek and Castro (2017) conclude that even with the control of the weather, behavioral and macroeconomic factors, the sell in May and go away strategy is to have a long position on the market from October 31 till April 30 effect persists in the market. Hayati et al., (2020) showed that there was no significant difference observed between the return of May-October, and November-April and reported about the absence of sell in May and go away effect in the Indonesia Stock Exchange.

v. Price to Earnings Ratio (PER): Latif et al., (2011) found that stocks with a high P/E ratio earn less return but stocks with a low $\mathrm{P} / \mathrm{E}$ ratio earn large risk-adjusted returns.

w. Reversal Effect (REV): De Bondt and Thelar $(1985,1987)$ found a winner-loser effect by observing that stock price deviates from the basic value due to investor's too pessimistic behavior about the past loser portfolio and too optimistic behavior about the past winner portfolio. But the market provides a chance after a while to correct its price and which turns the past winner return to the loser and past loser return to the winner.

x. Trading Rule and Technical Analysis (TRTA): According to Woo et al., (2020) by using some technical analysis tools and adopting some trading rules investor could make a significant amount of profit and considered this as an anomaly because investors can avail an opportunity to earn profit which further portrays that market is not efficient.

y. Tax Loss Selling (TLS): Tax-loss selling holds that people will sell down stock at the end of the year to achieve the purpose of paying fewer taxes. Gultekin and Gultekin (1983); 
Addinpujoartanto (2019) mentioned in the study that the tax-loss selling hypothesis is one of the factors of the January effect further states that Investors will do sell action which results in a decrease in stock prices to realize tax loses.

The factors affecting seasonality in the stock market are described above. There are numbers of factors that create an impact on seasonality; however, the prior studies have not considered all factors together to find out the most influencing factors. It represents that prior studies have not analyzed the factors with the SNA model. There remains a Research Gap which has been motivated the conduct of the present study for the analysis of various influencing factors with the help of the SNA model. In the first changing Global economy there remains a need for a recent study about the factors influencing the seasonality in the stock market. The finding of the paper will help the shareholder to take rational decision and help them to take the advantages of seasonal patterns to make an abnormal profit. This paper fills the gap of previous research on the seasonality effect that seldom analyzes the relationship between different influencing factors. It also provides a useful reference for future research studies from the perspective of investors and the stock market with the analysis of influencing factors.

\section{METHODOLOGY}

The study uses SNA to analyze the relationship between the factors affecting seasonality in the stock market. SNA was first introduced by Moreno (1934). SNA is a set of methodological tools that focus on the relationships among social entities and on the patterns and implications of these relationships (Wasserman \& Faust 1994). Both social structure and individual attributes can be examined simultaneously with the SNA (Kajol et al., 2020). This study focuses on the relationships of different factors of seasonality effect and seeks to identify both their causes and effects. While using the SNA, the study used different terms such as nodes, in-degree, outdegree, centrality, between's, network cohesion, network density, etc. These terms are explained below:

- Node: The establishment of a social network is based on two parts, one of these is nodes. Node is a point where multiple lines meet. A node is a basic unit of a data structure. A node represents the information contained in a single data structure. In a social network, individual may be represented as nodes in graph and the relation between them are represented as edges.

- Degree centrality: Degree centrality refers to how connected the node is. It helps to know about the distribution of nodes and how connected they are and the probability of being either highly or less highly connected.

- In-degree: In-degree of a vertex means the numbers of edges are coming into the vertex. It is denoted by deg+ (v). The in-degree of a node is equal to the number of edges with that node as the target.

- Out-degree: Out-degree of a vertex means the number of edges that are going out from the vertex. It is denoted by deg- (v). The total number of living vertices is known as out-degree.

- Centrality: Centrality shows the importance or weight of an individual in a network. Centrality refers to a group of the matrix that aims to quantify the influence or effect of a particular node in a network.

- Betweenness: Betweenness centrality is a measure of how often a node is a bridge between the other nodes.

- Network Cohesion: In social network analysis, the term network cohesion refers to a measure of the connectedness and togetherness among factors within a network. The greater the 
position the better is the program design. Cohesion is a measure of the functional strength of a module.

- Network Density: Network density is the proportion of ties that are connected out of all ties that could be connected. Higher density means the network is more connected.

\section{Data collection}

To screen out a reasonable list of factors influencing the seasonality effect in the financial market this study uses the Delphi technique. Delphi Technique is a structured communication technique or method which relies on a panel of experts knowing of the area requiring decision making. It is a widely used to gather data from respondents. At the same time, it allows aggregation of opinion related to real-world knowledge solicited from experts within certain topic areas. The Delphi Method is based on the assumption that group judgments are more valid than individual judgments.

This research first involved many of the previous research studies from which different responsible factors were identified. In this study, eight experts from the academic field were invited to join a Delphi panel. It was carried out for screening the seasonality effect of influencing factors. After the identification of factors, a questionnaire was prepared to explain the background and purpose of the research study. The same questionnaire was sent to eight respondents by email. After that, the responses were collected and the confirmation was done based on the majority of respondents. For a further comprehensive analysis, collected data were subsequently processed with the SNA method. The matrices were established in an Excel spreadsheet then transferred to one of the SNA software of UCINET for the analysis of social network data. It has access to read and write a multitude of a differently formatted text files as well as Excel files, and with the help of these files it can draw the diagrams of social networks by labeling and coloring the nods with one's recommendation.

\section{ANALYSIS AND FINDINGS}

This study used the SNA model to determine the impact of critical influencing factors and their interrelations. After the identification of factors and their relationship, a network diagram can be developed. The study used the UCINET package to develop the network graph as the SNA requires the assistance of computer software (Loosemore, 1998). The strong presentation of the UCINET package shows the efficient results and provides the numbers of analytical techniques such as cohesion, the centrality of multiple measures, etc. Nodes and links are the two important terms in social networking analysis for the formation of a complete network that depicts the relationship among all the factors.

The present study consists of 25 influencing factors and each of the factors is represented as blue color rhombus shape nodes in the network diagram. The link from one influencing factor to another represents the relationship between each node. The central part of the diagram depicts the most influencing factors. Here the most influencing factors mean those factors which directly or indirectly highly influence the other factor. The main objective of the study is to find the most influencing factor among all the mentioned factors. After completing the questionnaire method and coding all the factors with a matrix, a factor network can be developed. The factor network will appear with abundant information related to the influencing factor. The influencing factors are mapped as nodes and the connection between them is mapped by arrows. When no arrow between two nodes means there is no connection between the factors. When a node has a single arrowhead towards other nodes that means the relationship is unidirectional. When the 
arrowheads are present in both directions it means that the relationships between two nodes are bi-directional. A large number of arrows indicate the most connected factors among the other factors. Based on the data of the questionnaire survey, a factors network was established by analyzing the matrix of relationships among different factors. The network diagram of degree centrality obtained by using the UCINET package is shown in figure 1.

The formation of the network indicates that the research process is complex based on the relationship of all factors. In the network diagram, influencing factors are shown with rhombus shape nodes and these nodes are of different sizes. The size of the nodes indicates the impact of given nodes. For instance, all the small nodes such as TC, TRTA, REV, and PER are represented with small rhombus because these factors have minimum relations with other factors in the network.

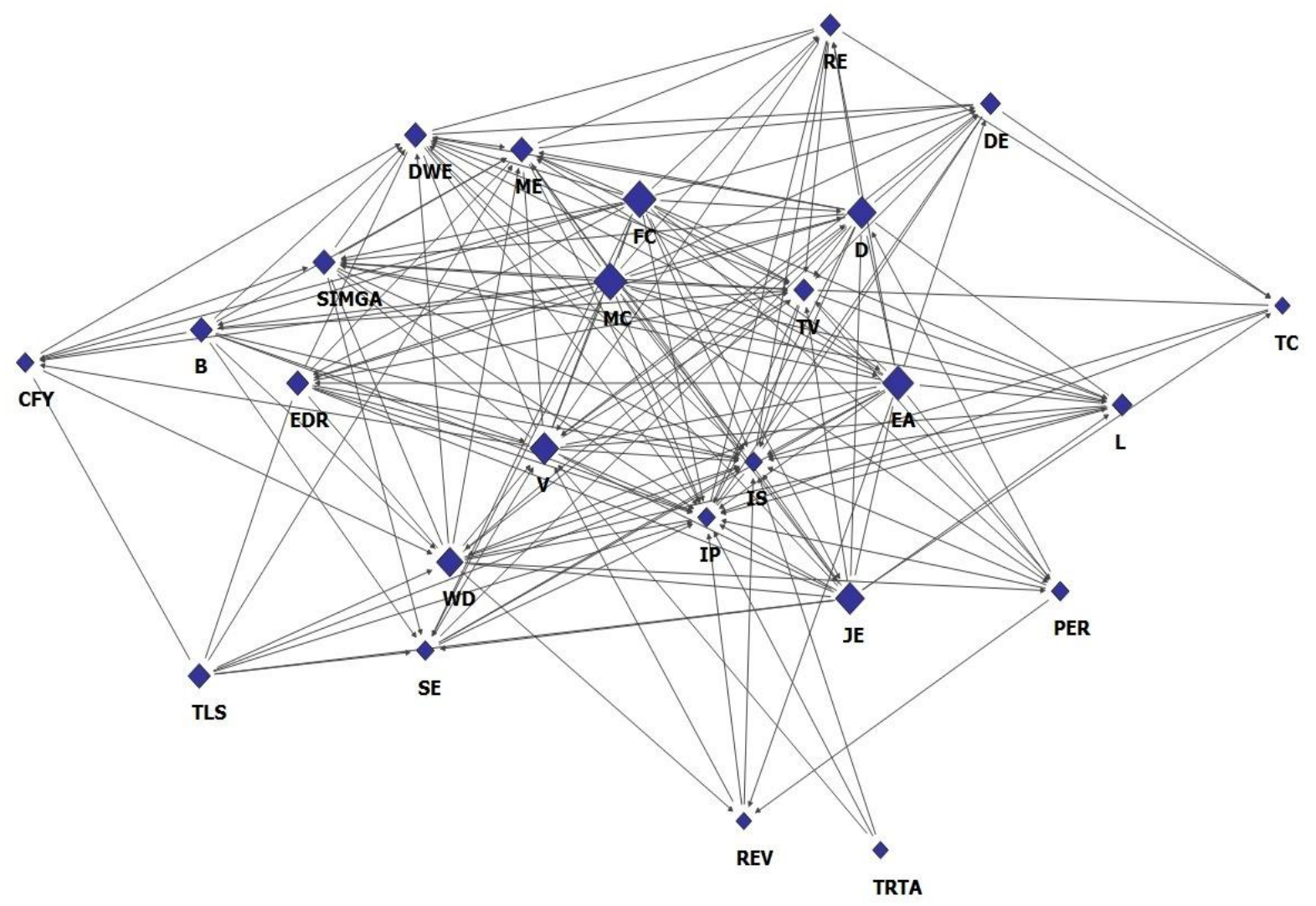

Figure 1.Degree Centrality of the factors influencing seasonality effect Source: Compiled by authors

FC, MC, EA, and JE are represented with larger nodes because of these factors have maximum out-degree relations in the network. The links between the two nodes represent the relationship between the nodes. The central part of the diagram represents highly influencing factors. Here, the highly influencing factors mean those factors which directly or indirectly impact most of the other factors. The data matrix collected by the questionnaire method, here, is represented as the complete factor network diagram. In SNA analysis, three types of measures are used for network analysis, such as network measures, node measures, and partition measures. 
These measures can be used to describe the structural arrangement of the influencing factor network in the seasonality effect. The visual representation of the data matrix consists of 219 ties and their compactness showing the value of 0.636. Network measures include density measure and cohesion measures that are usually used to describe the characteristics of an entire network. The network density of the present data set is 0.365 which means the network is not dense as compared to the density value and the average distance from one node to another is taken as 1.795 walks. To priorities the most influencing factor the study adopted the strategy to rank the factors worth more attention among them by introducing two indicators out-degree and indegree.

Table1 represents in-degree and out-degree of the influencing factors. A node's or a factor's in-degree centrality refers to the number of ties it received and out-degree centrality refers to the number of ties it sends. These two indicators expressed effects of the influencing factor from different perspectives.

Table 1. Degree Centrality of the factors influencing seasonality effect

\begin{tabular}{|c|c|c|c|}
\hline Factors & out-degree & Factors & in-degree \\
\hline MC & 19.000 & IS & 23.000 \\
\hline FC & 19.000 & IP & 23.000 \\
\hline EA & 17.000 & TV & 18.000 \\
\hline JE & 14.000 & V & 17.000 \\
\hline D & 14.000 & ME & 14.000 \\
\hline V & 14.000 & DWE & 13.000 \\
\hline WD & 12.000 & JE & 10.000 \\
\hline B & 9.000 & EDR & 10.000 \\
\hline DWE & 9.000 & WD & 9.000 \\
\hline EDR & 9.000 & L & 9.000 \\
\hline SIMGA & 9.000 & RE & 8.000 \\
\hline TLS & 8.000 & DE & 8.000 \\
\hline ME & 8.000 & SE & 8.000 \\
\hline RE & 7.000 & EA & 8.000 \\
\hline DE & 7.000 & D & 8.000 \\
\hline TV & 6.000 & SIMGA & 7.000 \\
\hline L & 6.000 & CFY & 5.000 \\
\hline PER & 5.000 & PER & 5.000 \\
\hline SE & 5.000 & TC & 4.000 \\
\hline
\end{tabular}




\begin{tabular}{|c|c|c|c|}
\hline IP & 5.000 & REV & 3.000 \\
\hline IS & 4.000 & TLS & 3.000 \\
\hline CFY & 4.000 & B & 2.000 \\
\hline TC & 3.000 & MC & 2.000 \\
\hline REV & 3.000 & FC & 2.000 \\
\hline TRTA & 3.000 & TRTA & 0.000 \\
\hline
\end{tabular}

Source: Compiled by authors

To categorize the extent of the relationship the factors, the out-degree, and in-degree centrality measures were divided into three parts (Kajol et al., 2020). The highest value of outdegree was 19 and the lowest value was 3 . The difference between highest and lowest, i.e., 16 were divided by 3 as our objective was to find out three levels of out-degree which comes out to be 5.33. So, the first-class interval of the out-degree value was between 3 (smallest value) to 8.33 $(3+5.33)$. Similarly, adding 5.33 with subsequent value, the next higher range was obtained. Thus, the following interpretation table was framed as given in table 2 .

Table 2. Interpretation of out-degree values

\begin{tabular}{|c|c|}
\hline Range of out-degree values & Interpretation \\
\hline $3-8.33$ & Least influential factors \\
\hline $8.33-13.66$ & Moderately influential factors \\
\hline $13.66-19$ & Highly influential factors \\
\hline
\end{tabular}

Source: Compiled by the authors

Based on table 2, it can be interpreted that MC, FC, EA, JE, D, and V are highly influential in influencing other factors of seasonality effect. WD, B, DWE, EDR, and SIMGA are moderately influencing the other factors of seasonality effect. The rest of the factors have a low impact on influencing other factors of the seasonality effect.

Similarly, the in-degree centrality measures were also categorized into three categories. The highest value of the in-degree centrality measure was 23 and the lowest value was 0 . The difference between highest and lowest was divided by three to ascertain their impact at three levels which comes out to be 7.67. So, the first-class interval of in-degree value was between 0 (smallest value) to $7.67(0+7.67)$. Similarly, adding 7.67 with subsequent value, the next higher range was obtained. Thus, the following interpretation table was framed as given in table 3 .

Table 3. Interpretation of in-degree values

\begin{tabular}{|c|c|}
\hline Range of in-degree values & Interpretation \\
\hline $0-7.67$ & Least influenced factors \\
\hline $7.67-15.34$ & Moderately influenced factors \\
\hline $15.34-23$ & Highly influenced factors \\
\hline
\end{tabular}

Source: Compiled by the authors 


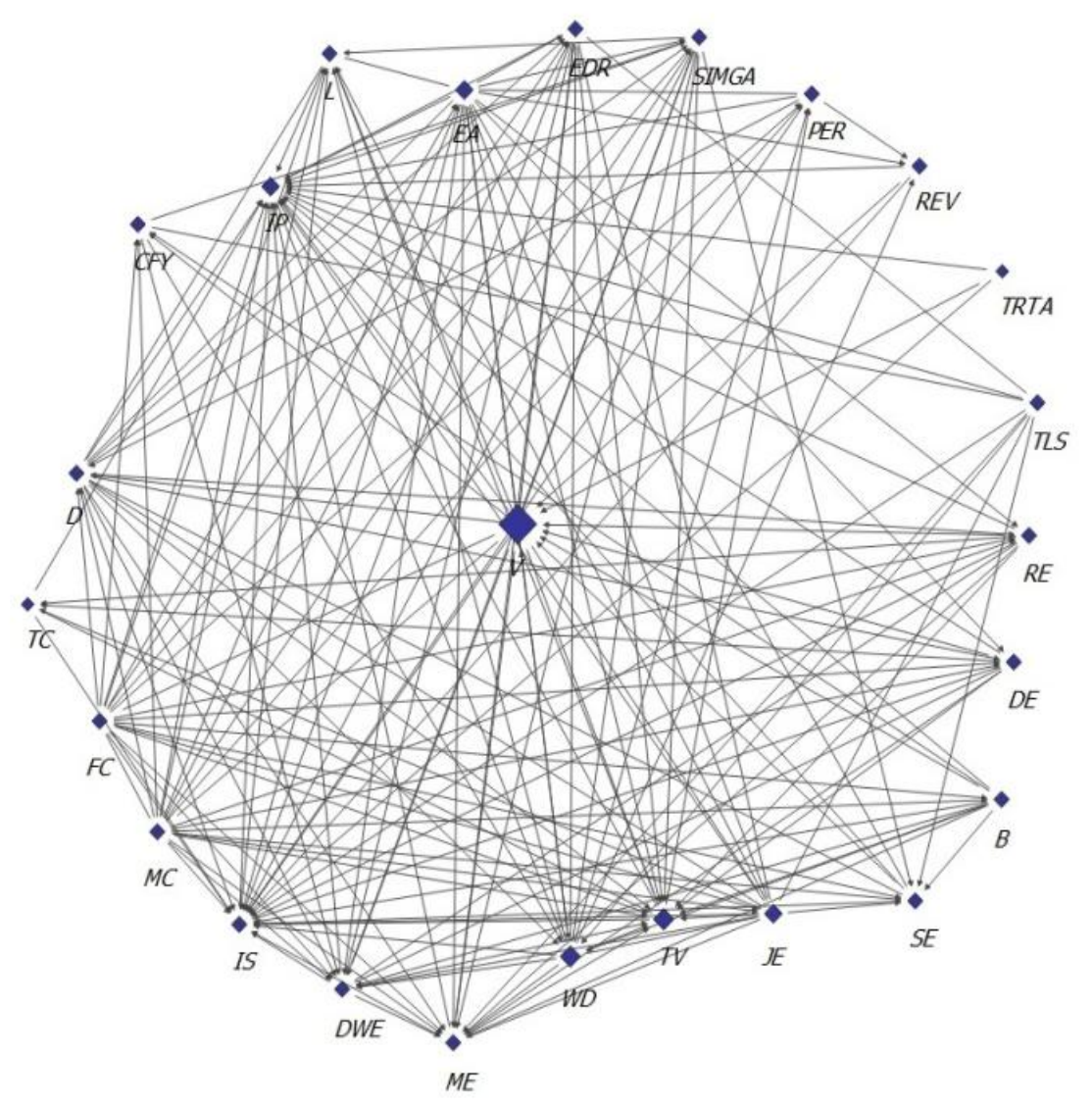

Figure 2. Betweenness Centrality of the factors influencing seasonality effect Source: Compiled by authors

Based on table 3, it can be deduced that IS, IP, TV, and V are highly influenced by other factors contributing to seasonality effect. ME, DWE, JE, EDR, WD, L, RE, DE, SE, EA, and D are moderately influenced by the other factors of seasonality effect. The rest of the factors are least influenced by the other factors.

Figure 2 shows the betweenness centrality of factors influencing the seasonality effect. Betweenness centrality measures the number of shortest paths passing through a node (Umadevi, 2013). The indicators of betweenness centrality express the degree to which a factor or an interrelation can control the impacts passing through. It is used to rank the factors based on the degree of control as an intermediary factor. Figure 2 shows that all the nodes positioned in the central location in the network diagram are most critical in controlling the other nodes. The extent of betweenness centrality of the nodes is represented through the size of the nodes. A node with a large rhombus has more control in connecting key nodes to other nodes in the network.

Table 4. Betweenness Centrality of factors influencing seasonality effect

\begin{tabular}{|c|c|c|c|}
\hline Factors & Betweenness Centrality & Factors & Betweenness Centrality \\
\hline V & 149.357 & DE & 11.459 \\
\hline TV & 41.883 & ME & 9.280 \\
\hline
\end{tabular}




\begin{tabular}{|c|c|c|c|}
\hline WD & 36.572 & PER & 7.298 \\
\hline JE & 29.041 & SIMGA & 7.044 \\
\hline IP & 27.559 & CFY & 5.517 \\
\hline EA & 27.369 & L & 4.551 \\
\hline D & 14.929 & SE & 4.235 \\
\hline DWE & 13.594 & TLS & 4.048 \\
\hline MC & 12.826 & REV & 2.500 \\
\hline FC & 12.826 & B & 0.250 \\
\hline IS & 12.637 & TC & 0.000 \\
\hline EDR & 11.765 & TRTA & 0.000 \\
\hline RE & 11.459 & & \\
\hline
\end{tabular}

Source: Compiled by authors

Table 4 shows the betweenness centrality of factors. The factors have been ranked according to the betweenness centrality value. Table 4 shows that Volatility has the highest betweenness centrality in the network which means it can control the impact of the maximum number of influencing factors. Same could be explained through Figure 2. The study has tried to categorize the factors into three levels of influence based on the betweenness centrality measure. The highest betweenness centrality measure was 149.357 and the lowest was 0 . The difference between the highest and lowest value of betweenness centrality was divided by three to determine the three levels of betweenness centrality which came out to be 49.79. So, the firstclass interval of betweenness centrality was ranged from 0 (smallest value) to $49.79(0+49.79)$. Similarly, 49.79 were added with subsequent value, to obtain the next higher range. Thus, the following interpretation table was framed as given in table 5.

Table 5. Interpretation of betweenness centrality values

\begin{tabular}{|c|c|}
\hline Range of betweenness centrality values & Interpretation \\
\hline $0-49.79$ & Least influential factors \\
\hline $49.79-99.58$ & Moderately influential factors \\
\hline $99.58-149.357$ & Highly influential factors \\
\hline
\end{tabular}

Source: Compiled by the authors

Based on table 5, it can be interpreted that $\mathrm{V}$ is the only highly influential factor and they can control the impact of the maximum number of influencing factors. It is interesting to observe here that no factor lies in the range of moderately influential factors. Therefore, the remaining twenty-four factors are categorized as the least influential factors that can control the impact of the minimum number of influential factors.

\section{DISCUSSION}

The framework set by the "seasonality effect" has profoundly created a business-ethical ambiance sum up with the stock market. "Seasonality Effect" which creates predictability in stock return has been identified as an important bias from which the investment decision is affected. This study connects some critical factors influencing the seasonality effect. 
Volatility was found to be an important influencing factor in the social network as it has the highest betweenness centrality (149.357) and high in-degree (17) \& out-degree (14) and therefore, portraits as a prime bridge among all the factors. It means that it can influence the other factor as well can be influenced by other factors at the same time. In figure 2 of betweenness centrality, it is clearly seen that the volatility node is concentrating at the center of the diagram. Heston and Sadka (2008) exhibit seasonality with intra-month volatility. Whenever new information enters the market stock prices fluctuate which leads to an increase in volatility in the market which further maximizes risk. The other factors influence the volatility more and the normal pattern or functioning of seasonal pattern gets disrupted.

Apart from volatility, factors such as earnings announcement, January effect, and dividends can also be considered as highly influential since they show either high out-degree centrality or high in-degree centrality. Nevertheless, it is important to note here that the betweenness centrality of the remaining 24 factors falls under the category of low influential factors. Thereupon, the major categorization of the influential factors is dependent on the degree of centralities.

Earning announcement and dividend act as a strong factor in the analysis and falls under high out-degree centrality. The out-degree of earning announcements and dividends were 17 and 14 respectively. Kim (2006) suggested that the risk factor is related to earnings information and the uncertainty is caused by earnings volatility. As the January effect is one of the most popular anomaly and well documented in the prior research, the present study also shows its out-degree to be 14 and in-degree to be 10.It means that the January effect can influence the other factor as well can be influenced by other factors at the same time. January month creates a major impact on the seasonality effect by providing higher returns during January. Gultekin and Gultekin (1983) explains that people in the USA sell their losing stock at the end of the year to pay less tax.

Analysis reveals the factor such as investors' sentiment, investors' psychology, trading volume; days of the week effect, window dressing, end-of-December return, market crash, and financial crisis moderately influence the seasonality effect in the stock market. The in-degree of investor's psychology is more than its out-degree which means that investor's psychology tends to be influenced by many influential factors in the network. As expected, the analysis indicates that investors' psychology has achieved the highest in-degree of 23 but at the same time low outdegree of 5. The finding of Bailkowski et al.,(2010) states that investors decision about the investment is very much impacted by their own belief and perception such as a high level of risk perception about equity investment leads to low investment by the investors (Singh \& Bhowal, 2009a; Singh \& Bhattacharjee, 2019). Al-Hajeh et al. (2011) state that positive and negative environments can change investors' sentiment and can become the driver of seasonality. Table 1 show that investors' sentiment also has the same high in-degree of 23 and lower out-degree i.e., 4, and performs as a moderate influential factor towards the seasonality. The relationship between seasonality effect, investors' psychology \& investors' sentiment was found to be moderately significant in the study.

This paper tries to establish the relationship between market crashes and other factors so their influence on seasonality can be identified. The out-degree of a market crash is more than its in-degree which means that the market crash is a moderate influential factor in the network. Market crashes were considered as a moderate influencing factor in the social network as it showed the out-degree of 19 and in-degree of 2.Accordingly, these factors can influence all other factors and can create an impact on the seasonality effect. Prior research such as Dash et al. 
(2011) found that market crash reduces seasonality. Similarly, Varadhrajan and Vikkraman (2011) found that during the general financial crisis a sharp fall was witnessed in the market capitalization as well as on the indices. The highest out-degree of 19 for financial crisis shows that it has a high influencing capacity but due to its low in-degree it moderately influences the other factors. As a result the poor stability of the market subsequently damages investors' portfolio and disturb the seasonal pattern.

Kang (2010) observed that a seasonal trading volume can affect a stock price; leading to a seasonal return pattern. From table 1 , it can be seen that the in-degree of trading volume is 18 which is comparatively high to other remaining factors but the out-degree falls under the least influential factor. The information implies that trading volume is moderate towards the seasonality effect. The SNA analysis of window dressing factor showed an out-degree of 12 and in-degree of 9, which is moderate towards seasonality. Days-of-week effect and end-ofDecember return were also regarded as a factor of moderate based on degree centralities.

The findings depicted that Ramadan effect, monthly effect, size effect, Diwali effect, sell-inmay and go away, liquidity, price-to-earning ratio, change in the financial year, transactional cost, tax-loss selling, reversal effect, budget \& trading rule and, technical analysis as low influential factors based on their degree as well as betweenness centralities. Husain (1998); Seyyed et al. (2005); Al-Hajieh et al. (2011) founds that during the Ramadan months stock return volatility declines as a result investors face less risk. Table 1 shows low out-degree and in-degree of Ramadan effect, as a result, the node of Ramadan effect in figure 1 is also small. Low degree centrality implies that the Ramadan effect's influence power is low toward seasonality. Boudreaux (1995) found that three out of seven countries' markets gave evidence of monthly effect in US stock. The monthly effect shows the in-degree of 14, which is moderate, and outdegree of 7, which is low and thus, it falls under the category of least influencing factor. The other factors such as size effect, Diwali effect, and liquidity fall under low degree centrality and depict the least significant in the study. Schabek and Castro (2017) reveals that with the control of the weather, behavioral and macroeconomic factors, the sell in May and go away strategy that is to have a long position on the market from October 31 till April 30 effect persists in the market. The out-degree and in-degree for sell in May and go away is consisted of 9 and 7 respectively and thus, has low influential feature towards seasonality. The budget is also one of the factors of the social network analysis provided with low degree centrality. Addinpujoartanto (2019) revealed that tax-loss selling is one of the factors of seasonality. The analysis revealed that tax-loss selling has a low influence on the seasonality effect.

The price-to-earnings ratio is consists of the same in-degree and out-degree ie., 5. Change in financial year price-to earnings ratio is found with low degree centrality and towards the seasonality as it falls under the low influencing factors. Transactional cost and reversal effect have a similar out-degree of 3 . The value implies that these factors have less influencing power. The analysis of the trading rule and technical analysis factor showed the out-degree of 3 and indegree of 0 , indicating that it cannot significantly influence other factors in the network.

\section{CONCLUSION AND POLICY IMPLICATION}

The present study concentrates on the factors that collectively impact the seasonality effect in the stock market and shows the most influencing factors and least influencing factors. The factors have been identified through the review of relevant literature on the seasonality effect and use of the Delphi technique in the study. The study used the SNA technique to determine the relationship between the identified factors. The study is unique as it has used the SNA technique 
in the concerned area for the first time. To determine the impact of factors on the existence of seasonality; degree centrality and betweenness centrality have been used in the study.

Volatility was found to be the most important factor in the network analysis. Volatility influence most of the other factors related to seasonality. Apart from volatility, it was found that earning announcements, dividend, and the January effects also strongly influence the effect of seasonality. However, the study reveals the factors such as investors' sentiment, investors' psychology, trading volume; days-of-week effect, window dressing, end-of-December return, market crash, and the financial crisis have a moderate influence on investors in respect of seasonality in the stock market. While the factors such as trading rule and technical analysis, price-to-earnings ratio, tax-loss selling, change in the financial year, reversal effect, monthly effect, liquidity, Ramadan effect, size effect, Diwali effect, sell-in-may and go away, budget \& transactional cost were least influencing factors.

The factors which are the most influential in the study should be provided high attention to minimize the seasonality effect. An investor should understand the functioning and their position in the market which will be possible when investors are aware of the market. Volatility was found to be the most important factor influencing the seasonality and therefore, investors should be given proper education about the market movements. So,to deal with the seasonality effect, it is essential to provide investor education (Singh \& Kar, 2011; Bhattacharjee \& Singh, 2017; Bordoloi et al, 2020). There should be a policy that the employer should impart investment education to its employees as a part of the employee benefits program (singh \& Bhowal, 2010). Since the dividend and earnings announcement are influencing seasonality so the major investment decision or disinvestment decision should be taken around these dates to capitalize on the benefit. A manager of a finance company or stock trading company can create a policy about their portfolio allocations efficiently considering these dates. Understanding the markets and the forces that drive the market trends can reduce the psychological and sentimental impact. Therefore, to change their psychology positively, SEBI should plan accordingly to minimize the seasonality effect, so that investors could find their desired direction. The managers of the fund houses and other institutional investors can design a campaign or create an attractive tagline to deal with investor's sentiment which can directly capture the sentiment of the investors. Furthermore, the culture of equity investing has to be promoted among the investors and this requires the use of concepts of marketing (Singh \& Bhowal, 2009b; Singh \& Bhowal, 2011).

The study also found that financial crisis and market crash as another important and strong factor for seasonality. Investor tries to sell all their good stocks out of panic and includes bad stocks in their portfolios because of the financial crisis and market crash (Singh, 2010b). Thus, before investing one should evaluate the fundamental worth of the company and, based on the fundamental only one should invest. This can be done by creating small investor education associations (Singh \& Bhowal, 2012). Another important point is that if an investor is going to invest in the equity they must also be aware of the fact that there is a risk associated with the investment that one has to bear. One should not go for any kind of investment for which the risk that they cannot bear. So, an effort should be made to promote an equity investment culture by training the investors on how to handle and manage high-risk scenarios (Singh, 2008; Singh, 2011; Singh \& Bhattacharjee, 2019).Some investors are enjoying the abnormal profit at the same time some investors are facing abnormal losses to seasonality. To control such activities authority/policy makers should prepare a policy about how to eliminate these factors and find a solution by mitigating the same. So, SEBI should focus on making investors aware of the seasonality and experience in this field, which can be done by launching an awareness 
campaigns and opening of Learning Investors' Club at different places (Singh \& Barman, 2011). An Increase in the investor's experience eventually decreases the seasonality effect and therefore, the investors should be given some experience of investing in the equity shares. Experience creates a vibrant change in the behavior of the people (Choudhury et al., 2016).

The study has presented some new findings for academicians. The categorization of the factors based on their influence has been done only in limited past research. Our approach to measuring the extent of the effect of the influential factors is new in the concerned area. No previous study was found dealing with possible differences between the influences of each of these factors. Apart from this, authors have found that trading rule and technical analysis, taxloss selling, reversal effect, price-to-earnings ratio, change in the financial year failed to show any significant impact on the other influential factors in the analysis. Therefore, the study calls for more research to examine the impact of these factors using other possible methodologies.

There prevail some research limitations in this study. Firstly, the study has identified the most influencing factor by SNA, but the path analysis factors and the level of influence in different factors are not clear. Secondly, all the invited experts for the survey were from the field of academics and have not included any stockbroker or investors for the expert panel. Another limitation is that primary focus was given to degree centrality and betweenness centrality measures though there are other measures of social network analysis like closeness centrality and Q-measure which were not taken into consideration. These limitations can impact the validity of future research. Therefore, the limitation will be taken into consideration in future research.

\section{REFERENCES}

Addinpujoartanto, N. A. (2019). Analysis of January effect on big stock companies and small stock companies at the Indonesia Stock Exchange. International Journal of Business, Humanities, Education and Social Sciences, 1(2), 47-56.

Ahsan, A. M. \& Sarkar, A. H. (2013). Does January Effect Exist in Bangladesh? International Journal of Business and Management, 8(7), 82-89.

Al-Hajieh, H., Redhead, K. \& Rodgers, T. (2011). Investor sentiment and calendar anomaly effects: A case study of the impact of Ramadan on Islamic Middle Eastern markets. Research in International Business and Finance, 25(3), 345-356.

Anjum, S. (2020). Impact of market anomalies on the stock exchange: a comparative study of KSE and PSX. Future Business Journal, 6(1), 1-11.

Bhattacharjee, J. \& Singh, R. (2017). Awareness about equity investment among retail investors: a kaleidoscopic view. Qualitative Research in Financial Markets, 9 (4), 310-324

Białkowski, J., Etebari, A. \& Wisniewski, T. P. (2012). Fast profits: Investor sentiment and stock returns during Ramadan. Journal of Banking \& Finance, 36(3), 835-845.

Bialkowski, J., Etebari, A. \& Wisniewski, T.P. (2010). Piety and Profits: Stock Market Anomaly during the Muslim Holy Month. Finance and Corporate, 44(0), 1-49.

Bordoloi, D., Singh, R., Bhattacharjee, J. \& Bezborah, P. (2020). Assessing the Awareness of Islamic Law on Equity Investment in State of Assam, India. Journal of Islamic Finance, 9(1), 001-012. 
Boudreaux, D. O. (1995). The monthly effect in international stock markets: evidence and implications. Journal of Financial and Strategic Decisions, 8(1), 15-20.

Choudhury, M., Singh, R., \& Saikia, H. (2016). Measuring Customer Experience in Bancassurance: An Empirical Study. Trziste, 28(1), 47.

Chowdhury, S. S. H., Sadique, M. S., \& Rahman, M. A. (2001). Capital market seasonality: The case of Dhaka stock exchange (DSE) returns. South Asian Journal of Management, 8(3), 17.

Cooper, M. J., McConnell, J. J., \& Ovtchinnikov, A. V. (2006). The other January effect. Journal of financial economics, 82(2), 315-341.

Das, P., \& Rao, S. P. (2011). Value Premiums and The January Effect: International Evidence. The International Journal of Business and Finance Research, 5(4), 1-15.

Dash, M., Sabharwal, M., \& Dutta, A. (2011). Seasonality and market crash in Indian Stock Markets. Available at SSRN 1785112.

De Bondt, W. F., \& Thaler, R. H. (1985). Does the stock market overreact? The Journal of Finance, 40(3), 793-805.

De Bondt, W. F., \& Thaler, R. H. (1987). Further evidence on investor overreaction and stock market seasonality. The Journal of Finance, 42(3), 557-581.

Easterday, K. E., Sen, P. K., \& Stephan, J. A. (2009). The persistence of the small firm/January effect: is it consistent with investors' learning and arbitrage efforts? The Quarterly Review of Economics and Finance, 49(3), 1172-1193.

Elsewarapu, V. R., \& Reinganum, M. (1993). The Seasonal Behavior of Liquidity Premium in Asset pricing. Journal of Financial Economics, 34(3), 373-386.

Fama, E. F. (1970). Efficient capital markets: A review of theory and empirical work. The journal of Finance, 25(2), 383-417.

Frankfurter, G. M., \& McGoun, E. G. (2001). Anomalies in finance: What are they and what are they good for? International review of financial analysis, 10(4), 407-429.

Gultekin, M. N., \& Gultekin, N. B. (1983). Stock market seasonality: International evidence. Journal of financial economics, 12(4), 469-481

Guo, S., \& Wang, Z. (2008). Market efficiency anomalies: A study of seasonality effect on the Chinese stock exchange (full-textbook).

Hayati, R., Irman, M., \& Agia, L. N. (2020). Sell in May and Go Away or Just Another January Effect? Studied of Anomaly in Indonesia Stock Exchange. International Journal of Economics Development Research (IJEDR), 1(1), 45-56.

Heston, S. L., \& Sadka, R. (2008). Seasonality in the cross-section of stock returns. Journal of Financial Economics, 87(2), 418-445. 
Husain, F. (1998). Seasonality in the Pakistani equity market: The Ramadhan effect. The Pakistan Development Review, 37(1) 77-81.

Jebran, K., \& Chen, S. (2017). Examining anomalies in the Islamic equity market of Pakistan. Journal of Sustainable Finance \& Investment, 7(3), 275-289.

Kajol, K., Biswas, P., Singh, R., Moid, S., \& Das, A. K. (2020). Factors affecting disposition effect in equity investment: A Social Network Analysis approach. International Journal of Accounting \& Finance Review, 5(3), 64-86.

Kang, M. (2010). Probability of information-based trading and the January effect. Journal of Banking \& Finance, 34(12), 2985-2994.

Keim, D. B. (1983). Size-related anomalies and stock return seasonality: Further empirical evidence. Journal of financial economics, 12(1), 13-32.

Keim, D. B. (1985). Dividend yields and stock returns: Implications of abnormal January returns. Journal of Financial Economics, 14(3), 473-489.

Keim, D. B., \& Stambaugh, R. F. (1984). A further investigation of the weekend effect in stock returns. The journal of finance, 39(3), 819-835.

Kim, D. (2006). On the information uncertainty risk and the January effect. The Journal of Business, 79(4), 2127-2162.

Kok, K. L., \& Wong, Y. C. (2004). Seasonal anomalies of stocks in ASEAN equity markets. Sunway Academic Journal, 1,1-11.

Kuria, A. M., \& Riro, G. K. (2013). Stock market anomalies: A study of seasonal effects on average returns of Nairobi securities exchange. Research journal of finance and accounting, 4(7), 207-215.

Kushwah, S. V., \& Munshi, M. S. (2018) The Effect of Seasonality over Stock Exchanges in India. Amity Journal of Management, 4(2) 46-53.

Lakonishok, J., \& Smidt, S. (1988). Are seasonal anomalies real? A ninety-year perspective. The review of financial studies, 1(4), 403-425.

Latif, M., Arshad, S., Fatima, M., \& Farooq, S. (2011). Market efficiency, market anomalies, causes, evidence, and some behavioral aspects of market anomalies. Research journal of finance and accounting, 2(9), 1-13.

Loosemore, M. (1998). Social network analysis: using a quantitative tool within an interpretative context to explore the management of construction crises. Engineering Construction and Architectural Management, 5(4), 315-326.

Majeed, U., Raheman, A., Sohail, M. K., Bhatti, G. A., \& Zulfiqar, B. (2015). Islamic calendar events and stock market reaction: Evidence from Pakistan. Science International, 27(3), 2559-2567. 
Milošević-Avdalović, S., \& Milenković, I. (2017). January effect on stock returns: Evidence from emerging Balkan equity markets. Industrija, 45(4), 7-21.

Mustafa, K., \& Nishat, M. (2008). Trading volume and serial correlation in stock returns in Pakistan. Philippine Review of Economics, 45(2), 1-11.

Reinganum, M. R. (1983). The anomalous stock market behavior of small firms in January: Empirical tests for tax-loss selling effects. Journal of financial economics, 12(1), 89-104.

Rozeff, M. S., \& Kinney Jr, W. R. (1976). Capital market seasonality: The case of stock returns. Journal of financial economics, 3(4), 379-402.

Safeer, M., \& Kevin, S. (2014). A study on market anomalies in the Indian stock market. International Journal of Business Administration Research Review, 1(3),128-137.

Schabek, T., \& Castro, H. (2017). "Sell not only in May". Seasonal Effect on Emerging and Developed Stock Markets. Dynamic Econometric Models, 17(1), 5-18.

Seyyed, F. J., Abraham, A., \& Al-Hajji, M. (2005). Seasonality in stock returns and volatility: The Ramadan effect. Research in International Business and Finance, 19(3), 374-383.

Singh, R. \& Barman, H. (2011). Learning Investors' Club. IMT Case Journal, 1(2), 39-47.

Singh, R. \& Bhowal, A. (2009b). Marketing Mix Driven Measure of Risk Perception in Respect of Equity Shares. Pacific Business Review, 2(2), 1-12

Singh, R. (2009). Behavioural Finance-A Kaleidoscopic View. BVIMSR's Journal of Management Research, 1(3), 313-321.

Singh, R. (2010a). Investors' Psychology and Equity Investment Decisions. Invertis Journal of Management, 2(2), 89-95

Singh, R. (2010b). Behavioural Finance Studies: Emergence and Developments. Journal of Contemporary Management Research, 4(2).

Singh, R. (2011). Equity investment culture and entrepreneurship culture-initiation and adaptation. Pacific Business Review International, 4(1), 66-71.

Singh, R., \& Bhattacharjee, J. (2019). Measuring Equity Share Related Risk Perception of Investors in Economically Backward Regions. Risks, 7(1), 12.

Singh, R., \& Bhowal, A. (2008). Risk Perception. The Theoretical Kaleidoscope. Vanijya, 18, 54-63.

Singh, R., \& Bhowal, A. (2009a). Risk perception dynamics and equity share investment behavior. Indian Journal of Finance, 3(6), 23-30.

Singh, R., \& Bhowal, A. (2010). Imparting investment education to employees by the employer: an expectation-experience gap study. Amity Management Analyst, 5(2), 57-65. 
Singh, R., \& Bhowal, A. (2011). Development of a marketing-driven measure of risk perception. The Journal of Risk Finance, 12(2), 140-152.

Singh, R., \& Bhowal, A. (2012). Marketing dimension of equity-related risk perception of employees: Own company's shares vs other company's shares. Management Insight, 6(2), 22-36

Singh, R., \& Kar, H. (2011). Do the highly educated subscribers aware of it? New pension scheme in India. SIBACA Management Review, 1(1), 8-16.

Singh, S., \& Das, C. (2020). Calendar Anomalies in the Banking and it Index: The Indian Experience. Asian Economic and Financial Review, 10(4), 439-448.

Thaler, R. H. (1987). Anomalies: The January effect. Journal of economic perspectives, 1(1), 197-201.

Ullah, I., Ullah, S., \& Ali, F. (2016). Market Efficiency Anomalies: A Study of January Effect In Karachi Stock Market. Journal of Managerial Sciences 10(1), 32-44.

Umadevi, V. (2013). Case study-centrality measure analysis on co-authorship network. Journal of Global Research in Computer Science, 4(1), 67-70.

Varadharajan, P., \& Vikkraman, P. (2011). Impact of Pre and Post Budget on Stock Market Volatility Between 2001 to 2011. Journal of contemporary research in management, 6(4), 49-64.

Wachtel, S. B. (1942). Certain observations on seasonal movements in stock prices. The journal of business of the University of Chicago, 15(2), 184-193.

Wasserman, S., \& Faust, K. (1994). Social network analysis: Methods and applications. Cambridge: Cambridge University Press.

Woo, K. Y., Mai, C., McAleer, M., \& Wong, W. K. (2020). Review on efficiency and anomalies in stock markets. Economies, 8(1), 20.

\section{APPENDICES}

Appendix A: Data Matrix of opinion of the experts showing the relationship among variables (1 denotes relationship'; 0 denotes

\begin{tabular}{|c|c|c|c|c|c|c|c|c|c|c|c|c|c|c|c|c|c|c|c|c|c|c|c|c|c|}
\hline & RE & $\overline{\mathrm{DE}}$ & B & SE & JE & TV & WD & ME & DWE & IS & $\mathrm{MC}$ & FC & TC & $\mathrm{D}$ & V & CFY & IP & $\mathrm{L}$ & $\overline{E A}$ & EDR & SIMGA & PER & REV & TRTA & TLS \\
\hline RE & 0 & 0 & 0 & 0 & 0 & I & 0 & I & I & I & 0 & 0 & I & 0 & I & 0 & I & 0 & 0 & 0 & 0 & 0 & 0 & 0 & 0 \\
\hline $\mathrm{DE}$ & 0 & 0 & 0 & 0 & 0 & I & 0 & I & I & I & 0 & 0 & I & 0 & $\mathrm{I}$ & 0 & I & 0 & 0 & 0 & 0 & 0 & 0 & 0 & 0 \\
\hline B & 0 & 0 & 0 & I & 0 & I & I & I & I & I & 0 & 0 & 0 & 0 & I & I & I & 0 & 0 & 0 & 0 & 0 & 0 & 0 & 0 \\
\hline $\mathrm{SE}$ & 0 & 0 & 0 & 0 & 0 & 0 & 0 & 0 & 0 & I & 0 & 0 & 0 & I & I & 0 & I & 0 & I & 0 & 0 & 0 & 0 & 0 & 0 \\
\hline $\mathrm{JE}$ & 0 & 0 & 0 & I & 0 & I & I & I & I & I & 0 & 0 & I & I & I & 0 & I & I & I & I & 0 & 0 & 0 & 0 & I \\
\hline TV & 0 & 0 & 0 & 0 & 0 & 0 & 0 & 0 & 0 & I & 0 & 0 & I & 0 & I & 0 & I & I & 0 & 0 & 0 & I & 0 & 0 & 0 \\
\hline WD & 0 & 0 & 0 & 0 & I & I & 0 & I & I & I & 0 & 0 & 0 & 0 & I & 0 & I & I & 0 & I & I & I & I & 0 & 0 \\
\hline
\end{tabular}




\begin{tabular}{|c|c|c|c|c|c|c|c|c|c|c|c|c|c|c|c|c|c|c|c|c|c|c|c|c|c|}
\hline $\mathrm{ME}$ & I & I & 0 & 0 & I & I & 0 & 0 & 0 & I & 0 & 0 & 0 & 0 & I & 0 & I & 0 & 0 & I & 0 & 0 & 0 & 0 & 0 \\
\hline DWE & I & I & 0 & 0 & I & I & 0 & $\mathrm{I}$ & 0 & I & 0 & 0 & 0 & 0 & I & 0 & I & 0 & 0 & I & 0 & 0 & 0 & 0 & 0 \\
\hline IS & I & I & 0 & 0 & 0 & I & 0 & 0 & 0 & 0 & 0 & 0 & 0 & 0 & 0 & 0 & I & 0 & 0 & 0 & 0 & 0 & 0 & 0 & 0 \\
\hline $\mathrm{MC}$ & I & I & I & I & I & I & 0 & $\mathrm{I}$ & $\mathrm{I}$ & $\mathrm{I}$ & 0 & I & 0 & I & I & I & I & I & $\mathrm{I}$ & I & $\mathrm{I}$ & $\mathrm{I}$ & 0 & 0 & 0 \\
\hline FC & I & I & I & I & I & I & 0 & $\mathrm{I}$ & $\mathrm{I}$ & $\mathrm{I}$ & $\mathrm{I}$ & 0 & 0 & $\mathrm{I}$ & I & I & I & I & $\mathrm{I}$ & $\mathrm{I}$ & $\mathrm{I}$ & $\mathrm{I}$ & 0 & 0 & $\overline{0}$ \\
\hline $\mathrm{TC}$ & 0 & 0 & 0 & 0 & 0 & I & 0 & 0 & 0 & I & 0 & 0 & 0 & 0 & 0 & 0 & I & 0 & 0 & 0 & 0 & 0 & 0 & 0 & 0 \\
\hline $\mathrm{D}$ & I & I & 0 & I & I & I & I & $\mathrm{I}$ & I & I & 0 & 0 & 0 & 0 & 0 & 0 & I & I & $\mathrm{I}$ & $\mathrm{I}$ & I & 0 & 0 & 0 & 0 \\
\hline $\mathrm{V}$ & 0 & 0 & 0 & 0 & I & I & 0 & I & I & I & $\mathrm{I}$ & I & 0 & I & 0 & I & I & I & I & $\mathrm{I}$ & I & 0 & 0 & 0 & 0 \\
\hline CFY & 0 & 0 & 0 & 0 & 0 & 0 & I & 0 & I & 0 & 0 & 0 & 0 & 0 & 0 & 0 & 0 & 0 & 0 & 0 & $\mathrm{I}$ & 0 & 0 & 0 & I \\
\hline IP & I & I & 0 & 0 & 0 & I & I & 0 & 0 & I & 0 & 0 & 0 & 0 & 0 & 0 & 0 & 0 & 0 & 0 & 0 & 0 & 0 & 0 & 0 \\
\hline $\mathrm{L}$ & 0 & 0 & 0 & 0 & 0 & I & 0 & 0 & 0 & $\mathrm{I}$ & 0 & 0 & 0 & $\mathrm{I}$ & I & 0 & I & 0 & $\mathrm{I}$ & 0 & 0 & 0 & 0 & 0 & 0 \\
\hline EA & I & I & 0 & I & I & I & I & $\mathrm{I}$ & $\mathrm{I}$ & $\mathrm{I}$ & 0 & 0 & 0 & I & I & 0 & I & I & 0 & $\mathrm{I}$ & $\mathrm{I}$ & $\mathrm{I}$ & I & 0 & 0 \\
\hline EDR & 0 & 0 & 0 & 0 & I & I & I & $\mathrm{I}$ & $\mathrm{I}$ & $\mathrm{I}$ & 0 & 0 & 0 & 0 & I & 0 & I & 0 & 0 & 0 & 0 & 0 & 0 & 0 & I \\
\hline SIMGA & 0 & 0 & 0 & I & 0 & I & I & I & I & I & 0 & 0 & 0 & 0 & I & 0 & I & I & 0 & 0 & 0 & 0 & 0 & 0 & 0 \\
\hline PER & 0 & 0 & 0 & 0 & 0 & 0 & 0 & 0 & 0 & I & 0 & 0 & 0 & I & 0 & 0 & I & 0 & I & 0 & 0 & 0 & I & 0 & 0 \\
\hline REV & 0 & 0 & 0 & 0 & 0 & 0 & 0 & 0 & 0 & I & 0 & 0 & 0 & 0 & I & 0 & I & 0 & 0 & 0 & 0 & 0 & 0 & 0 & 0 \\
\hline TRTA & 0 & 0 & 0 & 0 & 0 & 0 & 0 & 0 & 0 & $\mathrm{I}$ & 0 & 0 & 0 & 0 & I & 0 & I & 0 & 0 & 0 & 0 & 0 & 0 & 0 & 0 \\
\hline TLS & 0 & 0 & 0 & I & I & 0 & I & $\mathrm{I}$ & 0 & $\mathrm{I}$ & 0 & 0 & 0 & 0 & 0 & I & I & 0 & 0 & I & 0 & 0 & 0 & 0 & 0 \\
\hline
\end{tabular}

\section{Copyrights}

Copyright for this article is retained by the author(s), with first publication rights granted to the journal. This is an open-access article distributed under the terms and conditions of the Creative Commons Attribution license (http://creativecommons.org/licenses/by/4.0/) 